\title{
The Study Biological Aspects of Parapenaeopsis coromandelica on Cilacap Water, Central Java
}

\author{
Pramesti Budi Widyaningrum, Suradi Wijaya Saputra, Anhar Solichin
}

Program Studi Manajemen Sumberdaya Perairan

Jurusan Perikanan, Fakultas Perikanan dan Ilmu Kelautan, Universitas Diponegoro

Jl. Prof. H. Soedharto, SH. Tembalang Semarang 50275 Telp/Fax (024) 76480685

\begin{abstract}
ABSTRAK
Kabupaten Cilacap merupakan salah satu kabupaten yang memilki potensi yang tinggi di bidang perikanan tangkap karena terletak di pesisir pantai selatan Pulau Jawa dimana terdapat pangkalan perikanan yang terbesar. Pemanfaatan udang P.coromandelica yang terus meningkat, menyebabkan tingginya intensitas penangkapan dan menurunnya daya dukung lingkungan perairan Kab. Cilacap, hal ini memungkinkan perkembangan stok dari jenis udang ini terhambat. Tujuan dari penelitian ini adalah untuk mengetahui aspek biologi, status pemanfaatan dan konsep pengelolaan udang $P$. coromandalica di perairan Cilacap. Metode penelitian yang digunakan adalah metode survey, dengan teknik pengambilan sampel secara simple random sampling yaitu mengambil sampel udang sekitar $10 \%$ dari total hasil tangkapan salah satu alat tangkap jaring arad pada setiap TPI. Jenis data yang digunakan yaitu data primer dan data sekunder. Penelitian ini dilakukan pada bulan September - Desember 2012. Hasil penelitian menunjukkan bahwa Pertumbuhan udang P.coromandelica jantan dan betina memiliki nilai b 1,657 dan 2,22 ini menunjukan bahwa pertumbuhan udang bersifat allometrik negative. Sebagian besar udang P.coromandelica belum matang gonad dan belum siap memijah. faktor kondisi untuk udang P.coromandelica jantan dan betina menunjukkan 1,054 dan 1,117 bahwa tubuh udang kurus. Nisbah kelamin jantan dan betina adalah 1 : 1,545 artinya bahwa perairan Kab. Cilacap tersebut masih normal. Nilai $\mathrm{L}_{\mathrm{m}} 41 \mathrm{~mm}, \mathrm{~L}_{\mathrm{c} 50 \%} 37 \mathrm{~mm}$ dan nilai $\mathrm{L}_{\infty}$ jantan dan betina adalah 53,68 mm dan 64,21 mm. Nilai $\mathrm{L}_{\mathrm{c} 50 \%}$ lebih besar dari nilai setengah $\mathrm{L}_{\infty}$, itu berarti udang $P$. coromandalica sudah layak tangkap.
\end{abstract}

Kata kunci : Udang P.coromandelica, Aspek Biologi, Perairan Kab.Cilacap

\begin{abstract}
P.coromandelica is one of the shrimp species which breed and thrive in Cilacap waters. The increasing intensity of catch of this particular species causes steady decline in the carrying capacity of local waters which in turn hamper the stock recovery P.coromandelica in the area. In addition, the usage of environmentally harmful and indiscriminate fishing gears, such as the small-bottom trawl, adds further threat to the existence of the P.coromandelica in the area. Therefore, it is important that a study on marine resources in the area be held particularly on P.coromandelica which is the main commodity of Cilacap seafood. Survey method with simple random sampling is used in the research. The data used in this research are categorized into primary and secondary data. Samples for primary data are obtained from approximately $10 \%$ of total catch of one of the trawls in each seafood auction in the area of Cilacap The research shows that $\mathrm{b}$ value of the growth of P.coromandelica in Cilacap waters are 1,657 and 2,22. This means that the growth of the species in the area is allometric negative with most of the P.coromandelica are immature and have yet to grow gonad. Condition factors for male and female shrimp, with values of 1,054 and 1,117, shows that the shrimps are small in size. Sex ratio of the species in the area is shown to be normal with a value of $1 ; 1.545$. Lm value is $41 \mathrm{~mm}$ and $\mathrm{Lc}_{50 \%}$ is 37 $\mathrm{mm}$.
\end{abstract}

Keywords: P.coromandelica, Biological Aspects, Cilacap Waters. 


\section{Pendahuluan}

Kabupaten Cilacap merupakan salah satu kabupaten yang memilki potensi yang tinggi di bidang perikanan tangkap karena terletak di pesisir pantai selatan Pulau Jawa dimana terdapat pangkalan perikanan yang terbesar dengan luas wilayah 225.360, 840 ha dan luas sebaran penangkapan $5.200 \mathrm{~km}^{2}$.

Udang merupakan potensi sumberdaya hayati yang memegang peranan penting dalam komoditi ekspor. Nilai jual udang yang tinggi menyebabkan banyaknya permintaan dari luar negeri dan menjadikan ekspor udang sebagai penghasil devisa terbesar dari bidang perikanan. Tujuan ekspor utama udang adalah pasar Amerika Serikat kemudian Jepang. Ekspor udang Indonesia ke dua negara yakni Amerika Serikat (AS) dan Jepang selama 2011 mencapai 50.313 ton. Jumlah itu naik dibandingkan tahun 2010 yang sebesar 45.092 ton. ton (Dinas Kelautan dan Perikanan Kabupaten Cilacap, 2012).

Udang P.coromandelica, merupakan salah satu udang yang hidup dan berkembang biak di perairan Kabupaten Cilacap. Pemanfaatan udang P.coromandelica yang terus meningkat, menyebabkan tingginya intensitas penangkapan dan menurunnya daya dukung lingkungan perairan Kab. Cilacap, hal ini memungkinkan perkembangan stok dari jenis udang ini terhambat. Selain itu penggunaan alat tangkap seperti arad yang memiliki ukuran mata jaring kecil, tidak selektif dan tidak ramah lingkungan akan mengancam potensi udang P.coromandelica. Jika tidak segera dilakukan pengelolaan akan mengakibatkan overfishing atau bahkan kepunahan. Oleh karena itu perlu diadakannya sebuah kajian mengenai sumberdaya perikanan khususnya udang P.coromandelica yang merupakan komoditas dari perairan di Kabupaten Cilacap.

Tujuan dari penelitian ini adalah untuk mengetahui aspek biologi dan mengkaji ukuran mata jaring yang optimal untuk penangkapan udang P.coromandelica di perairan pantai Kab. Cilacap

\section{Materi dan Metode}

\subsection{Materi}

Materi yang digunakan pada penelitian ini adalah es batu sebagai pengawet dan udang P.coromandelica yang ditangkap nelayan dan didaratkan di tempat pelelangan ikan Kab. Cilacap. Alat yang digunakan dalam penelitian ini ada dua jenis yaitu alat lapangan dan alat labolatorium. Alat lapangan yaitu cool box. Alat labolatorium terdiri dari penggaris dengan ketelitian $1 \mathrm{~mm}$, timbangan elektrik ketelitian 0,01, buku identifikasi, lup (kaca pembesar), satu set alat sectio, sterofoam, jarum pentul, alat tulis.

\subsection{Metode}

Metode penelitian yang digunakan yaitu metode survey. Metode sampling yang digunakan dalam penelitian ini yaitu metode random sampling, yaitu metode pengambilan sampel secara acak. Sampel udang diambil secara proporsional yaitu sekitar $10 \%$ dari total hasil tangkapan salah satu alat tangkap jaring arad pada setiap TPI. Sampel yang didapatkan dipilah-pilah sesuai dengan jenis dan ukurannya. Pengambilan sampel dilakukan sebanyak 4 kali dari bulan September- Desember 2012.

\subsection{Analisis data}

\subsubsection{Hubungan panjang berat}

Analisa panjang berat menggunakan metode Effendie (2002), sebagai berikut:

$$
W=a L^{b}
$$

Keterangan :

$$
\begin{aligned}
& \mathrm{W} \quad=\text { Berat tubuh }(\text { gram }) \\
& \mathrm{L} \quad=\text { Panjang tubuh }(\mathrm{mm}) \\
& \text { a dan } b=\text { Konstanta }
\end{aligned}
$$

\subsubsection{Faktor kondisi}

Rumusan dalam analisa faktor kondisi ditentukan setelah sifat pertumbuhan panjang dan berat diketahui. Bila nilai $b \neq 3$, maka $K$ dihitung dengan rumus:

$$
K=\frac{W}{a L^{b}}
$$

\section{Keterangan :}

$$
\begin{array}{ll}
\mathrm{K} & =\text { Faktor kondisi } \\
\mathrm{W} & =\text { Berat udang }(\text { gram }) \\
\mathrm{L} & =\text { Panjang karapas udang }(\mathrm{mm}) \\
\mathrm{a} \text { dan } \mathrm{b}= & \text { konstanta }
\end{array}
$$




\subsubsection{Struktur Ukuran}

Perhitungan struktur ukuran meliputi panjang maksimal, panjang minimal, panjang rata-rata udang, dan panjang yang sering muncul (modus). Dihitung dengan statistik deskriptif dan disajikan dalam bentuk tabel histogram

\subsubsection{Ukuran Rata-Rata Tertangkap}

Ukuran rata-rata udang tertangkap didapatkan dengan cara memplotkan frekuensi kumulatif dengan setiap panjang udang, sehingga akan diperoleh kurva logistik baku, dimana titik potong antara kurva dengan $50 \%$ frekuensi kumulatif adalah panjang saat $50 \%$ udang tertangkap

\subsubsection{Ukuran Pertama Kali Matang Gonad}

Ukuran udang pertama kali matang gonad didapatkan dengan cara memplotkan frekuensi kumulatif dengan setiap panjang udang, sehingga akan diperoleh kurva logistik baku, dimana titik potong antara kurva dengan $50 \%$ frekuensi kumulatif adalah ukuran saat udang pertama kali matang gonad.

\subsubsection{Panjang Infinity $(L \infty)$}

Panjang infinty $(\mathrm{L} \infty)$ merupakan ukuran rata-rata panjang udang pada umur yang sangat tua. Menurut Pauly (1984) dalam Saputra (2009), perhitungan panjang infinty adalah sebagai berikut:

$\mathrm{L} \infty=\mathrm{L}_{\max } / 0,95$

Keterangan

$\mathrm{L}_{\max }=$ Panjang maksimum (mm)

\subsubsection{Selektivitas alat tangkap arad}

Menurut Saputra (2009), nilai selektivitas alat tangkap (SF) dapat dihitung dengan mengetahui nilai $\mathrm{L}_{50 \%}$ dan ukuran mata jaring pada kantong. Adapun rumus mencari nilai seleksivitas alat tangkap adalah sebagai berikut

$$
\mathrm{SF}=\frac{\mathrm{L} 50 \%}{\text { mesh size }}
$$

\section{Keterangan :}

$\mathrm{L}_{50 \%} \quad=$ ukuran udang pertama kali tertangkap $(\mathrm{mm})$

Mesh size $=$ ukuran mata jaring $(\mathrm{mm})$

\subsubsection{Nisbah Kelamin}

Nisbah kelamin dihitung dengan cara membandingkan jumlah udang jantan dengan jumlah udang betina dengan menggunakan uji chi-square (Hadi, 1984).

$$
\mathrm{X}^{2}=\Sigma\left[(\mathrm{fo}-\mathrm{fh})^{2} / \mathrm{fh}\right]
$$

Keterangan :

Fo $=$ Frekuensi udang jantan dan betina yang teramati

$\mathrm{fh}=$ frekuensi harapan, yaitu frekuensi udang jantan ditambah udang betina di bagi dua

$\mathrm{X}^{2}=$ Sebuah nilai bagi peubah acak $\mathrm{x}^{2}$

\section{Hasil dan Pembahasan}

\subsection{Struktur Ukuran}

Pengamatan ukuran bermanfaat untuk mengetahui identifikasi kohort, ukuran udang yang biasa tertangkap dan berhubungan dengan jenis alat tangkap apa yang digunakan sekaligus ukuran mesh sizenya. Histogram struktur ukuran dapat dilihat pada Gambar 1 

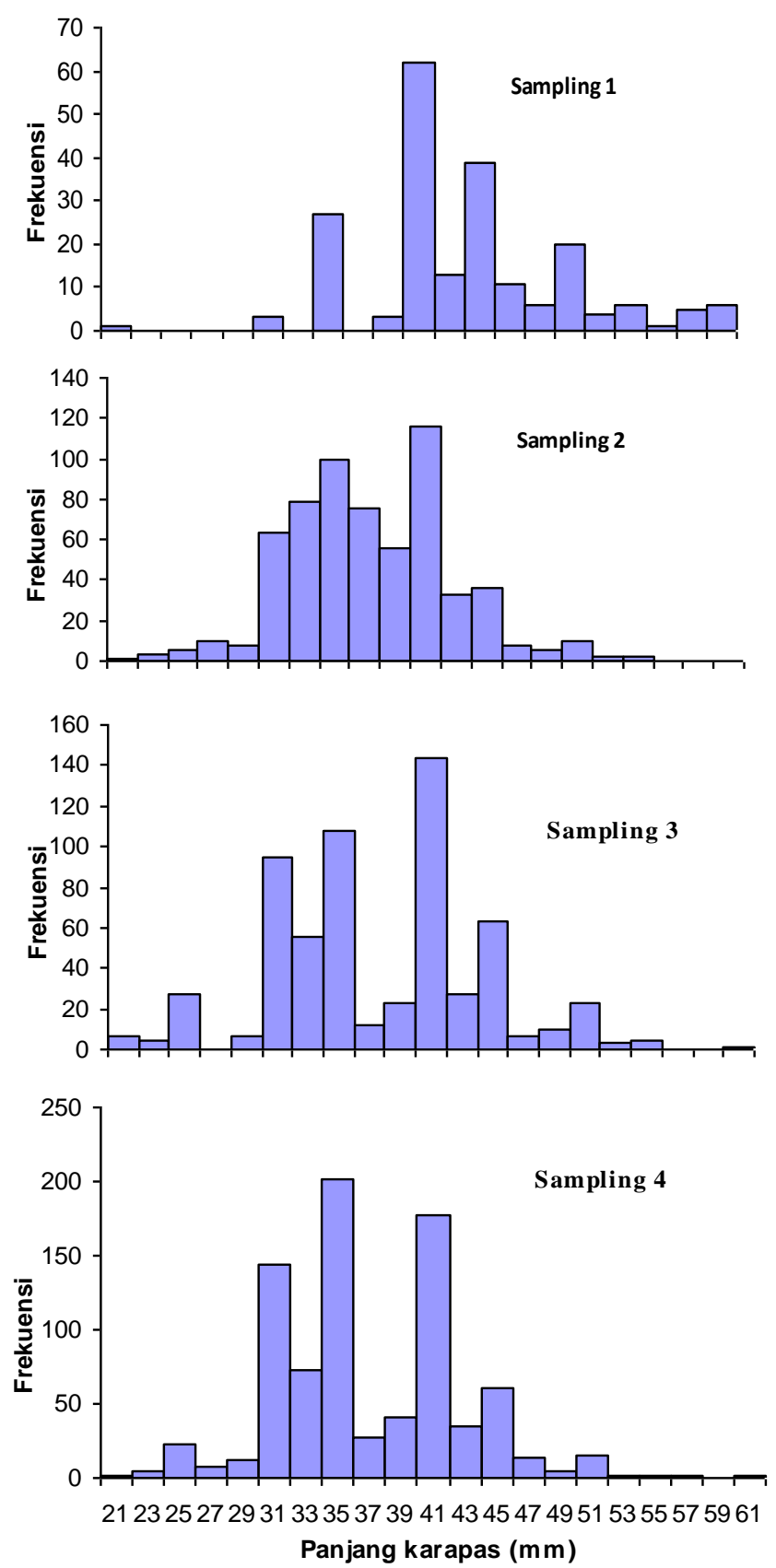

Gambar 1 . Struktur Ukuran Udang P.coromandelica

Panjang pada setiap sampling (Gambar 1) terlihat bahwa selama penelitan dari sampling pertama, hingga ketiga didapatkan modus nilai tengah panjang karapas udang berukuran $41 \mathrm{~mm}$. Pada sampling keempat terjadi pergeseran modus menjadi $35 \mathrm{~mm}$. Diduga masa tinggal kohort udang hanya berlangsung tiga bulan saja selanjutnya akan diganti oleh stok atau kelompok. 


\subsubsection{Ukuran Pertama Kali Tertangkap $\left(\mathrm{L}_{50 \%}\right)$}

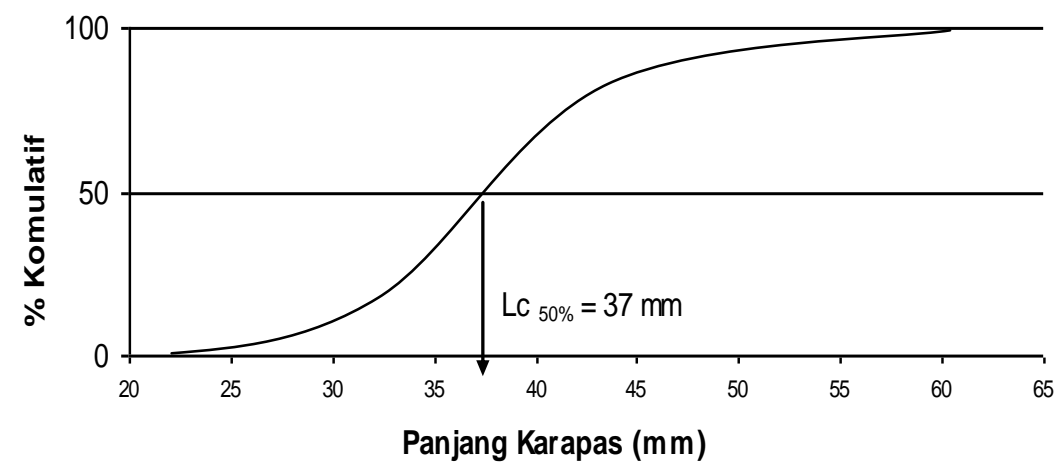

Gambar 2. Ukuran Pertama Kali Tertangkap $\left(\mathrm{L}_{\mathrm{c} 50 \%}\right)$ Udang P.coromandelica

Berdasarkan Gambar 2 ukuran rata-rata panjang karapas $\left(\mathrm{Lc}_{50 \%}\right)$ yang pertama tertangkap arad adalah $37 \mathrm{~mm}$. Alat tangkap arad yang digunakan dalam kegiatan penangkapan menggunakan mesh size sebesar 16 mm. Sedangkan nilai SF nya sebesar 2,31 mm. Ukuran pertama kali tertangkap $\left(\mathrm{L}_{\mathrm{c} 50 \%}\right)$ udang P.coromandelica adalah $37 \mathrm{~mm}$, dan mesh size jaring arad yang digunakan sebesar $16 \mathrm{~mm}$. Dengan diketahuinya nilai $\mathrm{L}_{\mathrm{c} 50 \%}$ dan ukuran mata jaring pada kantong, maka dapat kita hitung nilai SF dari jaring tersebut. Apabila faktor selektifitas alat tangkap telah kita dapat, maka dapat dirumuskan saran tindak pengelolaan perikanan, khususnya terkait dengan pengaturan ukuran mata jaring, agar ukuran udang yang tertangkap mendekati keinginan pengelola. Berdasarkan hasil penelitian didapatkan nilai SF 2,31 .

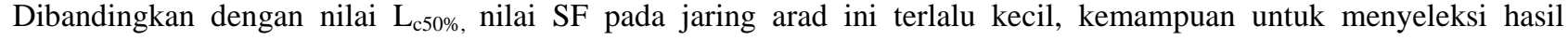
tangkapannya sangat rendah. Untuk itu, disarankan untuk mengatur jumlah alat tangkap dan ukuran mesh size yang digunakan dalam kegiatan penangkapan dan pengelolaan perikanan yang berkelanjutan.

\subsubsection{Panjang Infinty $(\mathrm{L} \infty)$}

Panjang infinty $(\mathrm{L} \infty)$ merupakan ukuran maksimal yang dapat dicapai oleh udang apabila tidak mengalami tekanan kematian dan penangkapan. Panjang infinity $(\mathrm{L} \infty)$ udang P.coromandelica selama penelitian tersaji pada Tabel 1 .

Tabel 1. Panjang Maksimal dan Panjang Infiniti $\left(\mathrm{L}_{\infty}\right)$ Udang P.coromandelica

\begin{tabular}{cccc}
\hline No & Jenis kelamin & L max & $\mathrm{L}_{\infty}$ \\
\hline 1 & Jantan & 51 & 53,68 \\
2 & Betina & 61 & 64,21 \\
\hline
\end{tabular}

Berdasarkan Tabel 1, nilai $\mathrm{L}_{\infty}$ pada udang betina 64,21 $\mathrm{mm}$ dan udang jantan 53,68 mm.Ukuran rata-rata udang P.coromandelica yang tertangkap $\left(\mathrm{L}_{50 \%}\right.$ ) yaitu $37 \mathrm{~mm}$. Jika dibandingkan dengan setengah panjang infiniti (Lo), ukuran pertama kali tertangkap tidak boleh kurang dari setengah dari panjang infiniti (L $\infty)$. Hal ini didukung oleh Saputra (2009), menyatakan bahwa ukuran pertama tertangkap idealnya tidak lebih kecil dari 0,5 x L $\infty$. Setengah panjang infinti $(\mathrm{L} \infty)$ yaitu $32,105 \mathrm{~mm}$, sehingga ukuran udang pertama kali tertangkap lebih dari setengah panjang infiniti $(\mathrm{L} \infty)$. Hal ini menunjukkan bahwa udang P.coromandelica sudah layak tangkap..

\subsection{Analisa hubungan panjang berat}

Hubungan panjang berat dalam penelitian ini dibuat berdasarkan jenis kelamin. Hasil perhitungan hubungan panjang dan berat udang jantan dan betina menggunakan analisis regresi linier dengan taraf kepercayaan $95 \%$, tersaji dalam Tabel 2 : 
Tabel 2. Parameter Hubungan Panjang Berat Udang P.coromandelica Jantan dan Betina

\begin{tabular}{cccc}
\hline & Parameter & \multicolumn{2}{c}{ Jenis kelamin } \\
\cline { 3 - 4 } No & $\mathrm{n}$ & Jantan & Betina \\
\hline 1 & Intersep (a) & 0,0095 & 0,0013 \\
2 & Slope (b) & 1,657 & 2,22 \\
3 & $\mathrm{~W}=\mathrm{aL}^{\mathrm{b}}$ & $\mathrm{W}=0,0095 \mathrm{~L}^{1,657}$ & $\mathrm{~W}=0,0013 \mathrm{~L}^{2,22}$ \\
4 & $\mathrm{R}^{2}$ & 0,987 & 0,984 \\
5 & $\mathrm{r}$ & 0,993 & 0,991 \\
\hline
\end{tabular}

Berdasarkan Tabel 2, nilai b yang diperoleh kurang dari 3, menunjukkan bahwa pertambahan panjang lebih cepat daripada pertambahan beratnya, sehingga termasuk allometrik negative.

Dari persamaan hubungan panjang berat tersebut dapat dibuat dalam bentuk grafik seperti yang tersaji dalam Gambar 3 berikut ini :

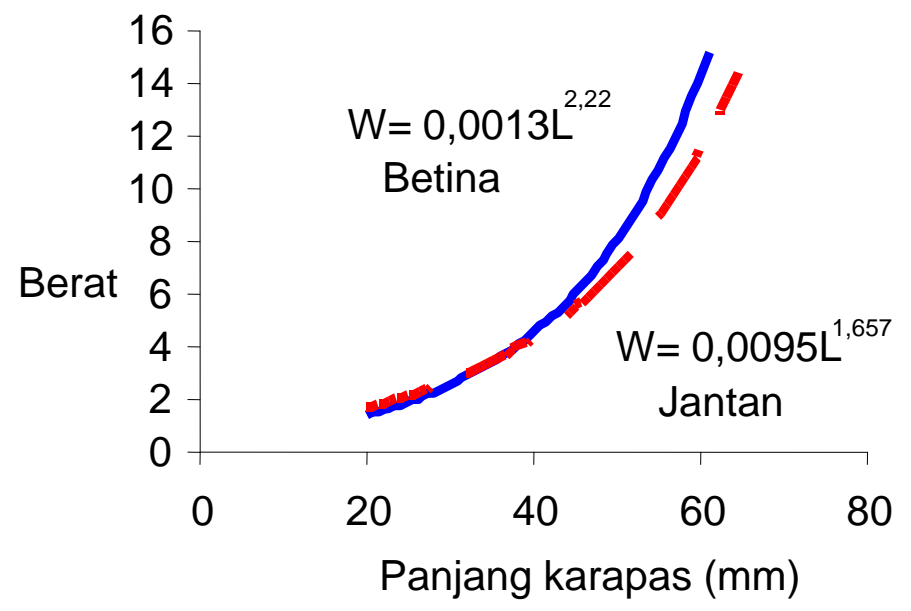

Gambar 3. Grafik Hubungan Panjang Berat Udang P.coromandelica Jantan dan Betina

Dari hasil penelitian diperoleh nilai $\mathrm{b}<3$ menunjukkan bahwa hubungan panjang berat udang P.coromandelica jantan dan betina memiliki pola pertumbuhan allometrik negatif, yaitu pertambahan panjang lebih cepat daripada pertambahan beratnya. Asbar (1994) menyatakan bahwa semakin tua umur udang, maka pertambahan berat akan lebih besar dibanding pertambahan panjang.

Hal ini dikarenakan semakin tua, pertumbuhan panjang akan berhenti dan hanya pertumbuhan berat yang bertambah. Dari hasil penelitian menunjukkan diduga udang masih dalam masa pertumbuhan dan belum maksimal, dari sini perlu diperhatikan usaha untuk menjaga supaya udang dapat tumbuh berkembang. Misalkan dalam usaha penangkapan dengan pembatasan besar mata jaring, sehingga hanya udang yang besar yang tertangkap dan udang yang kecil dapat terus tumbuh.

Faktor yang dapat mempengaruhi perbedaan pertumbuhan panjang dan berat antara lain faktor ekologi, makanan (kuantitas dan kualitas) dan faktor lain seperti jenis kelamin, umur, waktu dan area penangkapan (King,1995).

\subsection{Faktor kondisi}

Faktor kondisi merupakan suatu keadaan kemontokan udang yang dinyatakan dalam angka-angka berdasarkan pada panjang dan berat. Faktor kondisi pada pertumbuhan udang yang allometrik dicari dengan metode yang berbeda dengan faktor kondisi pada pertumbuhan udangyang isometrik. Dari data faktor kondisi yang diperoleh di lapangan tersaji dalam Tabel 3 : 
Tabel 3. Faktor Kondisi Udang P.coromandelica Jantan dan Betina

\begin{tabular}{cccccccc}
\hline $\begin{array}{c}\text { Jenis } \\
\text { kelamin }\end{array}$ & $\begin{array}{c}\text { Interval } \\
(\mathrm{mm})\end{array}$ & Frekuensi & $\begin{array}{c}\text { Intercept } \\
\text { (a) }\end{array}$ & $\begin{array}{c}\text { Slope } \\
\text { (b) }\end{array}$ & $\begin{array}{c}\text { Rata-rata } \\
\text { berat (gr) }\end{array}$ & $\begin{array}{c}\text { Rata-rata } \\
\text { panjang } \\
(\mathrm{mm})\end{array}$ & $\begin{array}{c}\text { Kn } \\
\text { Jantan }\end{array}$ \\
20-51 & 896 & 0,0095 & 1,657 & 3,572 & 34,7 & 1,054 \\
Betina & $20-61$ & 1386 & 0,0013 & 2,22 & 4,948 & 39,007 & 1,117 \\
\hline
\end{tabular}

Berdasarkan Tabel 3 nilai faktor kondisi dari udang P.coromandelica jantan yaitu 1,054 dengan panjang 34,7 mm dan berat 3,572 gr. Sedangkan pada udang betina memiliki nilai faktor kondisi 1,117 dengan panjang 39,007 mm dan berat 4,948 gr.

Perbedaan nilai Kn ini disebabkan oleh pengaruh ketersediaan makanan dan jenis kelamin. Udang P.coromandelica jantan memiliki nilai Kn yang lebih kecil dibanding udang betina. Hal ini disebabkan karena berat udang betina bertambah karena adanya gonad dalam tubuhnya. Selain itu bisa juga dikarenakan ukuran betina akan cepat bertambah besar setelah matang gonad tetapi tidak demikian pada udang jantan (Hartnoll, 1982 dalam Ristianti, 2005).

Besar kecilnya faktor kondisi yang dihasilkan diduga karena adanya perbandingan yang tidak seimbang antara panjang karapas dan berat udang. Karapas jantan dan betina berpengaruh karena pertumbuhan panjang dan berat tubuh udang yang tidak terbatas, tetapi ukuran karapas tidak ikut bertambah. Hal ini disebabkan oleh kenaikan frekuensi molting, dapat meningkatkan atau justru dapat menurunkan kecepatan untuk tumbuh. Udang yang sedang molting memiliki kulit lebih lunak dan ringan sehingga beratnya juga jadi lebih ringan, tetapi udang yang molting bisa saja bertambah berat karena banyaknya molekul air yang terserap oleh karapas udang (Hartnoll, 1982 dalam Ristianti, 2005).

\subsection{Tingkat kematangan gonad}

Pengamatan tingkat kematangan gonad yang dilakukan selama penelitian ini menggunakan metode King (1995). Berikut ini adalah hasil pengamatan TKG pada udang P.coromandelica tersaji pada Tabel 4:

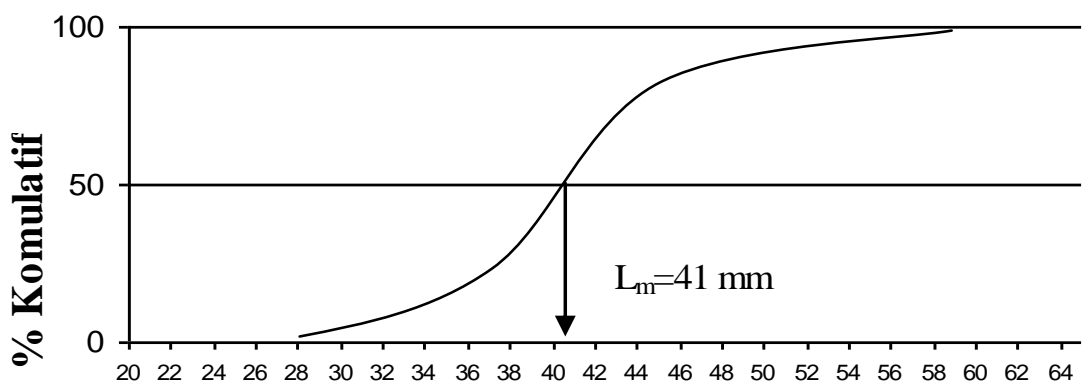

Panjang karapas (mm)

Gambar 4 . Ukuran Pertama Kali Matang Gonad $\left(\mathrm{L}_{\mathrm{m}}\right)$ Udang P.coromandelica Betina

Ukuran pertama kali matang gonad udang P.coromandelica betina $41 \mathrm{~mm}$, sedangkan pada ukuran pertama kali tertangkap $37 \mathrm{~mm}$.

Ukuran udang saat pertama kali matang gonad penting diketahui terutama dengan kaitannya dengan pengelolaan. Berdasarkan hasil penelitian, didapatkan nilai $\mathrm{L}_{\mathrm{m}}$ sebesar $41 \mathrm{~mm}$. Ukuran pertama kali matang gonad dapat digunakan untuk mengetahui apakah udang tersebut sudah pernah memijah atau belum. Caranya dengan membandingkan ukuran udang dengan nilai $\mathrm{L}_{\mathrm{m}}$ nya. Jika ukuran udang tersebut lebih besar daripada nilai $\mathrm{L}_{\mathrm{m}}$ nya maka udang tersebut sudah pernah memijah, jika belum pernah memijah maka nilainya akan lebih kecil dibandiingkan nilai $\mathrm{L}_{\mathrm{m}}$. Misalnya saja, jika ada udang yang berukuran besar tapi memiliki TKG yang rendah, sedangkan udang yang berukuran kecil memiliki TKG yang tinggi, itu berarti yang memiliki TKG tinggi baru mengalami pematangan gonad untuk pertama kalinya, sedangkan yang memiliki TKG kecil tapi berukuran besar itu berarti sudah mengalami pemijahan. Kecepatan matang gonad, sangat mempengaruhi dalam reproduksi. Semakin cepat gonad matang maka kemungkinan terjadinya pembuahan akan menjadi lebih cepat (Motoh, 1997 dalam Ristianti, 2005). 
Panjang karapas pertama kali matang $\left(\mathrm{L}_{\mathrm{m}}\right)$, sering disebut juga sebagai panjang karapas $50 \%$ matang. Perbandingan antara ukuran pertama kali matang gonad dan ukuran pertama kali tertangkap membutuhkan data ukuran panjang dan TKG dari udang betina. Hal ini dikarenakan lebih banyak udang betina yang matang goand daripada udang jantan. Nilai $\mathrm{L}_{\mathrm{m}}$ dapat dibandingkan dengan nilai $\mathrm{L}_{\mathrm{c} 50 \%}$, perbandingan ini dapat digunakan untuk melihat apakah udang yang tertangkap lebih banyak yang sedang memijah atau sedang dalam masa pertumbuhan. Dari hasil penelitian diperoleh nilai $\mathrm{L}_{\mathrm{m}}$ sebesar $41 \mathrm{~mm}$ sedangkan nilai $\mathrm{L}_{\mathrm{c} 50 \%} 37 \mathrm{~mm}$

\subsubsection{Nisbah kelamin}

Hasil penelitian menunjukkan perbandingan udang P.coromandelica jantan dan betina tersaji dalam Tabel 4:

Tabel 4. Nisbah Kelamin Udang P.coromandelica

\begin{tabular}{cccc}
\hline No & Jenis kelamin & Jumlah (ekor) & $\begin{array}{l}\text { Perbandingan } \\
\text { jantan: betina }\end{array}$ \\
\hline 1 & Jantan & 897 & $1: 1,545$ \\
2 & Betina & 1386 &
\end{tabular}

Berdasarkan Tabel 4, perbandingan jantan dan betina udang P.coromandelica adalah 1 : 1,545. Hasil perhitungan nisbah kelamin menunjukkan bahwa udang $P$.coromandelica betina lebih banyak daripada jantan. Menurut Darmono (1991), pada perairan normal memiliki perbandingan udang jantan dan betina 1:1. Jumlah udang betina yang lebih banyak daripada udang jantan, menguntungkan karena pada saat musim pemijahan sel telur akan lebih besar peluangnya untuk dibuahi sel sperma sehingga kesempatan mempertahankan populasinya lebih besar.

Perbandingan udangP.coromandelica jantan dan betina adalah 1:1,545 berarti perairan Kab. Cilacap masih bisa dibilang normal. Udang betina jumlahnya lebih banyak daripada udang jantan dalam suatu perairan, hal ini mungkin dikarenakan pada masa bertelur jumlah udang jantan akan menurun karena udang jantan akan mati lebih awal. Selain itu juga dapat dikarenakan masa pertumbuhan udang betina yang lebih cepat sehingga udang betina memiliki ukuran yang lebih besar sekaligus memiliki pergerakan yang cepat, sehingga dapat digunakan untuk menghindar dari predator.

Menurut Naamin (1984), apabila di suatu perairan terjadi tekanan penangkapan yang tidak begitu tinggi, maka selalu ditemui udang betina lebih banyak dari udang jantan, namun ini akan sebaliknya apabila terjadi aktivitas penangkapan yang berlebihan, dikhawatirkan akan berkurangnya jumlah udang betina pemijah tersebut.

\section{Kesimpulan dan Saran}

\subsection{Kesimpulan}

Berdasarkan hasil penelitian yang telah dilakukan dapat diambil kesimpulan sebagai berikut:

1. Aspek biologi udang P.coromandelica :

- Pertumbuhan udang P.coromandelica bersifat alometrik negatif, terlihat pertumbuhan panjang yang lebih cepat daripada beratnya;

- Sebagian besar udang P.coromandelica belum matang gonad dan belum siap memijah;

- Nilai faktor kondisi untuk udang P.coromandelica menunjukan betina lebih montok dari jantan

- Keseluruhan nilai $\left(\mathrm{L}_{\mathrm{c}}\right)$ memenuhi syarat keberlanjutan, yaitu tidak kurang dari setengah nilai $\mathrm{L}_{\infty}$

2. Pengaturan ukuran mata jaring dapat dilakukan dengan cara membuat mesh size harapan, agar ukuran udang yang tertangkap mendekati keinginan.

\subsection{Saran}

Saran yang dapat disampaikan penulis pada penelitian adalah sebagai berikut:

1. Masih diperlukan penelitian lebih lanjut tentang udang P.coromandelica, sehingga didapatkan informasi yang lebih lengkap tentang kondisi udang P.coromandelica di perairan Kabupaten Cilacap.

2. Data sebagai sarana pengelolaan sangat penting sehingga diharapkan pencatatan data bisa lebih lengkap dan teratur.

\section{Ucapan Terimakasih}

Ucapan terimakasih ditujukan kepada Ir. Moch. Harmanto, MM selaku kepala Dinas Kelautan dan Perikanan yang telah membantu memeberikan data produksi dan ijin untuk melakukan penelitian di Kabupaten Cilacap. Serta kepala TPI Menganti, TPI Lengkong, TPI Kemiren dan TPI Tegal Katilayu. Ucapan terimakasih ditujukan pula kepada Dr. Ir. Suradi Wijaya Saputra, M.S dan Ir. Anhar Solichin, M.Si atas bimbingannya dalam penyusunan penelitian ini. 


\section{DAFTAR PUSTAKA}

Asbar. 1994. Hubungan Tingkat Eksploitasi dengan Struktur Populasi dan Produksi Udang Windu Penaeus monodon

(F) di Segara Anakan. Program Pascasarjana, Institut Pertanian Bogor. Bogor. (Thesis S3).

Darmono, 1991. Budidaya Udang Penaeus. Kanisius Yogyakarta.

DKP. 2012. Potensi udang. http://www.dkp.go.id (21 September 2012)

Effendie, M.I. 2002. Biologi Perikanan. Yayasan Pustaka Nusatama. cetakan kedua. Yogyakarta.

Hadi, S. 1984. Metode Riset. Yayasan Penerbit Fakultas Psikologi UGM.

King, M. 1995. Fisheries Biology, Assessment and Management. Fishing New Books. Faculty of Fisheries and Marine Environment Australian Maritime College. Victoria.

Naamin, N 1984. Dinamika Populasi Udang Jerbung (Penaeus merguensis). Di Perairan Arafuru dan Alternatif Pengelolaannya. [Disertasi]. Bogor Fakultas Pasca Sarjana IPB

Ristianti, I. 2005. Kajian Beberapa Aspek Biologi Udang Torpedo (Parapenaeopsis maxillipedo Alcock) di Perairan Segara Anakan Cilacap Jawa Tengah. [Skripsi] (tidak dipublikasikan) FPIK. UNDIP. Semarang.

Saputra, S.W. 2009. Dinamika Populasi Ikan. Badan Penerbit Universitas Diponegoro. Semarang.

Tritondo, L.N. 2008. Komposisi Hasil Tangkapan Udang Dan Laju Tangkap Pukat Udang di Perairan Arafura (Studi Kasus PT Irian Marine Product Development). [Skripsi]. Institut Pertanian Bogor, Bogor. 8 